\title{
Epidemiology of ossification of the spinal ligaments and associated factors in the Chinese population: a cross-sectional study of 2000 consecutive individuals
}

Haifeng Liang ${ }^{1+}$, Guobing Liu ${ }^{2 \dagger}$, Shunyi Lu', Shuguang Chen², Dongjie Jiang ${ }^{1}$, Hongcheng Shi ${ }^{2^{* \dagger}}$ and Qinming Fei ${ }^{1{ }^{*}+}$

\begin{abstract}
Background: The epidemiology and cause of ossification of the spinal ligaments (OSL) remains obscure. To date, there is no study that comprehensively evaluates the prevalence, distribution, and concomitance of each type of OSL by CT among general Chinese population. We therefore aimed to comprehensively investigate epidemiological characteristics of OSL using whole spine $C T$ in the Chinese population and examine the factors that correlate with the presence of OSL.

Methods: Ossification of the posterior longitudinal ligament (OPLL), ligamentum flavum (OLF), anterior longitudinal ligament (OALL), nuchal ligament (ONL), and diffuse idiopathic skeletal hyperostosis (DISH) were evaluated from the subjects who underwent PET/CT for the purpose of cancer screening in our hospital. Prevalence, distribution, and concomitance of OSL were reviewed. Logistic regression analysis was performed to identify the risk factors of OSL.

Results: A total of 2000 subjects (1335 men and 665 women) were included. The prevalence rate of cervical OPLL (COPLL) was 4.1\%, thoracic OPLL (T-OPLL) 2.25\%, lumbar OPLL (L-OPLL) 0.8\%, thoracic OLF (T-OLF) 37.65\%, lumbar OLF (LOLF) 1.45\%, ONL 31.5\%, DISH 3.85\%. The most commonly involved level was C5 for C-OPLL, T1 for T-OPLL, T10 for T-OLF, and T8/9 for OALL. 21\% of subjects with C-OPLL had T-OPLL, 44\% of C-OPLL had T-OLF, 38\% of T-OPLL had C-OPLL, 53\% of T-OPLL had T-OLF, 44\% of L-OPLL had T-OPLL, and 56\% of L-OPLL had T-OLF. The average age of OSL-positive subjects was significantly higher than that of OSL-negative subjects. The results of the multiple regression analysis revealed that males had a strong association with DISH (odds ratio, 3.15; 95\% confidence interval, 1.27-7.78; $P=0.013$ ).

Conclusion: The prevalence of OSL in the Chinese was revealed. Tandem ossification is not uncommon in people with OSL. There is a high incidence of multiple-regional OPLL in the whole spine. Approximately half of the subjects with OPLL coexist with T-OLF. For patients with clinical symptoms induced by OPLL, thorough evaluation of whole spine using $C T$ is recommended.
\end{abstract}

Keywords: Whole spine, Computed tomography, Ossification, Spinal ligament, Epidemiology, Prevalence, Posterior longitudinal ligament, Ligamentum flavum, Diffuse idiopathic skeletal hyperostosis

\footnotetext{
*Correspondence: shi.hongcheng@zs-hospital.sh.cn; fei.qinming@zs-

hospital.sh.cn

${ }^{\dagger}$ Hongcheng Shi and Qinming Fei contributed equally to this work and should be regarded as co-corresponding authors.

${ }^{\dagger}$ Haifeng Liang and Guobing Liu contributed equally to this work and should be regarded as co-first authors.

2Department of Nuclear Medicine, Zhongshan Hospital, Fudan University, F B1, Building 16, 180 Fenglin Road, Shanghai 200032, People's Republic of China

'Department of Orthopedic Surgery, Zhongshan Hospital, Fudan University, Building 1, 180 Fenglin Road, Shanghai 200032, People's Republic of China
}

(c) The Author(s). 2019 Open Access This article is distributed under the terms of the Creative Commons Attribution 4.0 International License (http://creativecommons.org/licenses/by/4.0/), which permits unrestricted use, distribution, and reproduction in any medium, provided you give appropriate credit to the original author(s) and the source, provide a link to the Creative Commons license, and indicate if changes were made. The Creative Commons Public Domain Dedication waiver (http://creativecommons.org/publicdomain/zero/1.0/) applies to the data made available in this article, unless otherwise stated. 


\section{Background}

Ossification of the spinal ligaments (OSL) is a pathologic condition characterized by heterotropic ossification of the spinal ligaments, such as ossification of the posterior longitudinal ligament (OPLL), ligamentum flavum (OLF), anterior longitudinal ligament (OALL), nuchal ligament (ONL) and diffuse idiopathic skeletal hyperostosis (DISH) $[1,2]$. OPLL and OLF are common causes of spinal stenosis and spinal cord compression, which can cause various degrees of neurological symptoms [3, 4]. But many affected individuals are usually asymptomatic when the lesions are small [5]. DISH is a skeletal disease characterized by progressive ossification of the anterolateral side of the spine [6]. Although $\mathrm{DISH}$ is thought to be an asymptomatic condition in most affected individuals not aware of its presence, several clinical symptoms have been reported including pain, restriction of spinal movements, dysphagia at cervical level, and increased risk of unstable spinal fractures after trauma [7, 8]. To today, there have been several epidemiological investigations in the Far East Asian population, especially in Japanese. However, researches have been rarely conducted among Chinese population.

The epidemiology and etiology of OSL remains obscure. According to our review of the literature, there have been only three researches reporting the prevalence of OSL in the Chinese population [9-11]. Lang et al. [10] reported that the prevalence of thoracic OLF (T-OLF) was $63.9 \%$ in Chinese patients $(n=993)$ with chest symptoms using chest CT. Guo et al. [9] reported that the prevalence of T-OLF was $3.8 \%$ in Chinese individuals $(n=1736)$ using MRI. And it must be noted that their study population had a much younger average age of 38 years. Wang et al. [11] reported that the prevalence of ONL was $49.7 \%$ in Chinese patients $(n=372)$ with cervical spondylosis using plain radiographs and $\mathrm{CT}$. Until now, no epidemiological study has assessed the prevalence of the OPLL, DISH, and OALL in Chinese population. And computed tomography (CT) may be the best modality for detecting the OSL, because it has a high resolution on density and can eliminate the influence of overlapping [12].

In light of this, the aim of this study was to comprehensively evaluate epidemiological characteristics of each type of OSL using whole body CT scans in the Chinese population and examine the factors that correlate with the presence of OSL.

\section{Methods}

\section{Participants}

From October 2010 to September 2013, a total of consecutive 2059 Chinese individuals from East China who underwent fluorin-18 fluorodeoxyglucose positron emission tomography and CT (PET/CT) for the purpose of cancer screening in our hospital were selected. Exclusion criteria were age of younger than 20 years or a history of spine surgery. If more than one CT scan were taken within the study period, the last examination was selected for the present study. As a result, 2000 subjects (1335 men and 665 women) were recruited for the analysis. Demographic data, including age, sex, height, weight and body mass index (BMI), were retrospectively reviewed. This study has been approved by our institutional ethics committee.

\section{Radiographic assessment}

To our knowledge, there is no universally agreed upon definition of OSL on CT. We therefore made a diagnosis of OSL according to previous researches with some modifications. Definitive OPLL and OLF were defined as the ossification, at least, thicker than $2 \mathrm{~mm}$ on axial CT scan [13-17]. OALL was defined as ossification thicker than $3 \mathrm{~mm}$ on axial CT scan and need to bridge the adjacent vertebrae $[16,18]$. DISH was diagnosed according to the commonly used diagnostic criteria, defined by Resnick and Niwayama [19]. The criteria are as follows: (1) the presence of contiguous ligamentous ossification involving three or more intervertebral disk levels(4 or more consecutive fused vertebral bodies) with anterior or lateral bridging; (2) preserved intervertebral disc space; and (3) absence of apophyseal joint ankylosis and sacroiliac joint fusion (Fig. 1).

For statistics on the prevalence and distribution of OSL, if OPLL was located at C7/T1 or T12/L1 intervertebral level, they were included in the cervical and thoracic segments, respectively. Similarly, OALL, bridging the adjacent vertebrae at $\mathrm{C} 7 / \mathrm{T} 1$ or $\mathrm{T} 12 / \mathrm{L} 1$ intervertebral level, were included in the cervical and thoracic segments, respectively. Pelvic and spinal sagittal parameters were measured on the midline sagittal image (Fig. 1). Cervical lordosis (C2-7, CL), thoracic kyphosis (T4-12, TK), and lumbar lordosis (L1-S1, LL) were measured by Cobb method. Sacral slope (SS) was measured between the tangent line to the superior endplate of S1 and the horizontal line. Sagittal vertical axis (SVA) was the distance between the $\mathrm{C} 7$ plumb line and the posterosuperior corner of S1. Cobb angles measured from supine CT may be underestimated compared with standing radiograph Cobb measurements. But supine CT curve measurements are also valuable in biomechanical analysis, because the supine position provides an approximate "zero load" configuration for the spine [20].

All whole body CT scans were obtained on a PET/ CT scanner (Discovery VCT, General Electric, Milwaukee, Wisconsin, USA) with the following settings: tube current $200 \mathrm{~mA}$, tube voltage $140 \mathrm{kV}$, thickness 


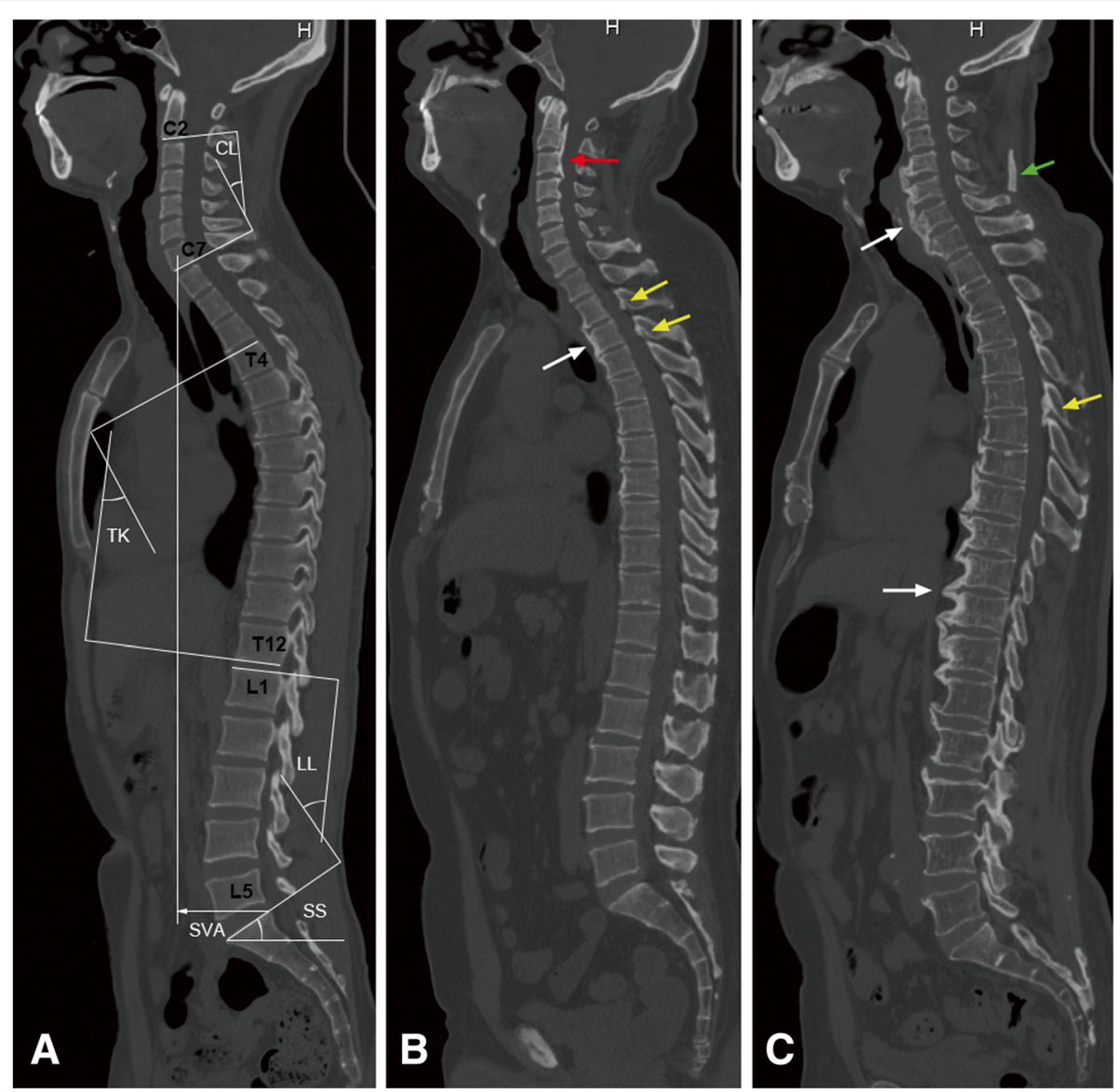

Fig. 1 Sagittal radiologic parameters and examples of each type of OSL on whole spine computed tomography. a Measurement methods for CL, TK, LL, SS, and SVA. b A 50-year-old man had OPLL (red arrow), OLF (yellow arrow), and OALL (white arrow). c A 70-year-old man had OLF (yellow arrow), DISH (white arrow), and ONL (green arrow). Abbreviations: CL, cervical lordosis; TK, thoracic kyphosis; LL, lumbar lordosis; SS, sacral slope; SVA, sagittal vertical axis; OPLL, ossification of the posterior longitudinal ligament; OLF, ossification of the ligamentum flavum; OALL, ossification of the anterior longitudinal ligament; DISH, diffuse idiopathic skeletal hyperostosis; ONL, ossification of the nuchal ligament

$3.75 \mathrm{~mm}$, collimation $64 \times 0.6 \mathrm{~mm}$, pitch 0.516 , matrix $512 \times 512$, and gantry rotation time $0.33 \mathrm{~s}$. Scanning was performed from head to mid-thigh in the supine position. Reconstructed axial and sagittal images were reviewed on a uWS-MI R001 workstation (United Imaging).

Images were reviewed in the following steps. Firstly, an orthopaedic spine surgeon and a radiologist independently evaluated 50 subjects from the enrolled cases. Disagreements were resolved by discussion with another senior orthopedic surgeon in a consensus meeting. Secondly, for testing the reliability of diagnoses, two observers independently evaluated another 100 subjects to assess the interobserver reliability. Once again, any differences were resolved by consensus. And then, the orthopaedic spine surgeon analyzed the 100 subjects again with a six weeks interval to assess the intraobserver reliability. Finally, the remaining subjects were reviewed by the orthopedic surgeon.

\section{Statistical analysis}

The data were analyzed using IBM SPSS 22.0 statistical software (IBM SPSS Inc., Armonk, NY, USA). Categorical data analyzed using chi-square or Fisher's exact tests. Measurement data analyzed using Student t test or Welch test. Logistic regression analysis was used to test the association between OSL and potential risk factors. Explanatory variables, such as age $(+1$ year $)$, gender $(0=$ women, $1=\mathrm{men})$, and height $(+1 \mathrm{~cm})$, identified by the univariate logistic regression analysis as potential risk factors were selected for inclusion in a multivariate logistic regression analysis. To ensure selection of the best combination of explanatory variables, only those with a $P<0.05$ were included in the model.

Kappa analysis was performed to determine interobserver and intraobserver reliabilities. Kappa values above $0.81,0.61-0.80,0.41-0.60,0.21-0.40$, and $0-0.20$ indicated almost perfect, substantial, moderate, fair and slight agreements, respectively [21]. For all analyses, statistical significance was set at a level of $P<0.05$. 


\section{Results}

The Kappa value of inter- and intra-observer reliabilities were 0.71 and 0.90 , respectively.

\section{Demographic data}

A total of 2000 subjects were included, there were 1335 men and 665 women. Table 1 displays the demographic characteristics of the study population. The mean age of the subjects was $48.5 \pm 9.9$ years(range, 22 to 95 years), height was $167.4 \pm 7.8 \mathrm{~cm}$, body weight was $68.8 \pm 12.6$ $\mathrm{kg}$, and BMI was $24.4 \pm 3.3 \mathrm{~kg} / \mathrm{m}^{2}$. The average regional Cobb angles were as follows: CL $7.9 \pm 6.2^{\circ}$, TK $18.3 \pm$ $7.7^{\circ}$, and LL $40.6 \pm 10.5^{\circ}$. The mean value of SS and SVA were, respectively, $36.9 \pm 7.5^{\circ}$ and $18.7 \pm 19.7 \mathrm{~mm}$.

\section{Prevalence, distribution, and concomitance of OPLL}

A total of 82 subjects had cervical OPLL (C-OPLL), including 55 men and 27 women. The prevalence of C-OPLL was $4.1 \%$ (men, 4.12\%; women, $4.06 \%$ ). A total of 45 subjects had thoracic OPLL (T-OPLL), including 21 men and 24 women. The prevalence of T-OPLL was $2.25 \%$ (men, $1.57 \%$; women, $3.61 \%$ ). A total of 16 subjects had lumbar OPLL (L-OPLL), including 10 men and 6 women. The prevalence of L-OPLL was $0.8 \%$ (men, $0.75 \%$; women, $0.9 \%$ ). The statistically significant difference between men and women was only in the prevalence of T-OPLL ( $p=0.004)$ (Table 2, Fig. 2).

Most of OPLL were located in the cervical spine (C2-C7/T1). The upper thoracic spine (T1-T6) and thoracolumbar junctional region (T11-L1/2) were less frequently involved (Fig. 3). The highest involvement of OPLL was most commonly detected at C5 (40 cases), followed by C6 (34 cases), C4 (31 cases), C3 (17 cases), C7 (17 cases), and T1 (16 cases). Figure 3 showed similar distribution between men and women in each region of the spine. However, the distribution of OPLL for

Table 1 Demographic data of the study subjects

\begin{tabular}{llll}
\hline Parameters & Total & Men & Women \\
\hline Number & 2000 & 1335 & 665 \\
Age $(\mathrm{y})$ & $48.5 \pm 9.9$ & $48.3 \pm 9.7$ & $48.9 \pm 10.2$ \\
Height $(\mathrm{cm})$ & $167.4 \pm 7.8$ & $171.4 \pm 5.6$ & $159.4 \pm 5.2$ \\
Weight $(\mathrm{kg})$ & $68.8 \pm 12.6$ & $68.8 \pm 12.6$ & $58.1 \pm 8.4$ \\
$\mathrm{BMI}\left(\mathrm{kg} / \mathrm{m}^{2}\right)$ & $24.4 \pm 3.3$ & $25.2 \pm 3.2$ & $22.9 \pm 3.1$ \\
$\mathrm{CL}\left({ }^{\circ}\right)$ & $7.9 \pm 6.2$ & $7.8 \pm 6.3$ & $8.0 \pm 6.1$ \\
$\mathrm{TK}\left({ }^{\circ}\right)$ & $18.3 \pm 7.7$ & $19.3 \pm 7.7$ & $16.5 \pm 7.5$ \\
$\mathrm{LL}\left({ }^{\circ}\right)$ & $40.6 \pm 10.5$ & $40.1 \pm 10.4$ & $41.6 \pm 10.8$ \\
$\mathrm{SS}\left({ }^{\circ}\right)$ & $36.9 \pm 7.5$ & $36.9 \pm 7.3$ & $37.0 \pm 7.9$ \\
$\mathrm{SVA}(\mathrm{cm})$ & $1.87 \pm 1.97$ & $2.32 \pm 2.11$ & $0.97 \pm 1.23$ \\
\hline BMI body mass & & $\mathrm{CL}(\mathrm{crvi}$ &
\end{tabular}

$B M I$ body mass index, $C L$ cervical lordosis, $T K$ thoracic kyphosis, $L L$ lumbar lordosis, SS sacral slope, SVA sagittal vertical axiss women showed two peaks with the highest and second highest peak found at $\mathrm{C} 5$ and $\mathrm{T} 1$, respectively.

Of all cases of C-OPLL, $21 \%$ had T-OPLL, $4 \%$ had L-OPLL, 44\% had T-OLF, 46\% had ONL, 21\% had cervical OALL (C-OALL), 52\% had thoracic OALL (T-OALL), and $17 \%$ had DISH. Of all cases of T-OPLL, $38 \%$ had C-OPLL, $16 \%$ had L-OPLL, $53 \%$ had T-OLF, $22 \%$ had C-OALL, $60 \%$ had T-OALL, $40 \%$ had ONL, and $18 \%$ had DISH. Of all cases of L-OPLL, 19\% had C-OPLL, $44 \%$ had T-OPLL, 56\% had T-OLF, and $44 \%$ had ONL.

\section{Prevalence, distribution, and concomitance of OLF}

A total of 5 subjects had cervical OLF (C-OLF), including 3 men and 2 women. The prevalence of C-OLF was $0.3 \%$ (men, $0.2 \%$; women, $0.3 \%$ ). A total of 753 subjects had T-OLF, including 482 men and 271 women. The prevalence of T-OLF was $37.7 \%$ (men, 36.1\%; women, $40.8 \%$ ). A total of 29 subjects had lumbar OLF (L-OLF), including 14 men and 15 women. The prevalence of L-OLF was $1.5 \%$ (men, 1.0\%; women, $2.3 \%$ ). The differences between men and women were statistically significant in the prevalence of T-OLF and L-OLF $(p<0.05)$. There was no significant difference in the prevalence of C-OLF between men and women $(p=1.000)$ (Table 2 , Fig. 2).

Most of OLF were located in the thoracic spine. The distribution of T-OLF formed two peaks with the highest and second highest peak found at $\mathrm{T} 10$ and $\mathrm{T} 4$, respectively (Fig. 3). T-OLF was found mostly at T10 (482 cases), followed by T9 (285 cases), and T11 (239 cases). Figure 3 showed similar distribution between men and women.

Of all cases of T-OLF, $5 \%$ had C-OPLL, $3 \%$ had T-OPLL, 4\% had L-OLF, 25\% had T-OALL, 36\% had ONL, and 6\% had DISH.

\section{Prevalence, distribution, and concomitance of OALL}

A total of 132 subjects had C-OALL, including 105 men and 27 women. The prevalence of C-OALL was $6.6 \%$ (men, 7.9\%; women, 4.1\%). A total of 383 subjects had T-OALL, including 296 men and 87 women. The prevalence of T-OALL was 19.2\% (men, 22.2\%; women, 13.1\%). A total of 39 subjects had lumbar OALL (L-OALL), including 33 men and 6 women. The prevalence of L-OALL was $2 \%$ (men, $2.5 \%$; women, $0.9 \%$ ). Statistical analysis showed that the prevalence of C-OALL, T-OALL, and L-OALL were significantly higher among the males $(P<0.05)$ (Table 2, Fig. 2).

Most of OALL were located in the thoracic spine. Three of the most commonly affected levels were T8/9 (152 cases), T9/10 (142 cases), and T3/4 (128 cases). The distribution of T-OALL showed two peaks in men but only one peak in women (Fig. 3). 
Table 2 Prevalence of each type of spinal ligament ossification

\begin{tabular}{lllll}
\hline & Total & Prevalence (\%) & \\
\cline { 3 - 5 } & & Men & Women & P \\
\hline C-OPLL & $4.10[3.23-4.97]$ & $4.12[3.05-5.19]$ & $4.06[2.56-5.56]$ & 0.949 \\
T-OPLL & $2.25[1.60-2.90]$ & $1.57[0.90-2.24]$ & $3.61[2.19-5.03]$ & 0.004 \\
L-OPLL & $0.80[0.41-1.19]$ & $0.75[0.29-1.21]$ & $0.90[0.18-1.62]$ & 0.717 \\
C-OLF & $0.25[0.03-0.47]$ & $0.22[0-0.48]$ & $0.30[0-0.72]$ & 1.000 \\
T-OLF & $37.65[35.52-39.78]$ & $36.10[33.53-38.68]$ & $40.75[37.01-44.50]$ & 0.043 \\
L-OLF & $1.45[0.93-1.97]$ & $1.04[0.50-1.60]$ & $2.26[1.12-3.39]$ & 0.033 \\
C-OALL & $6.60[5.51-7.69]$ & $7.86[6.42-9.31]$ & $4.06[2.56-5.56]$ & 0.001 \\
T-OALL & $19.15[17.42-20.88]$ & $22.17[19.94-24.40]$ & $13.08[10.51-15.65]$ & $<0.001$ \\
L-OALL & $1.95[1.34-2.56]$ & $2.47[1.64-3.31]$ & $0.90[0.18-1.62]$ & 0.017 \\
ONL & $31.50[29.46-33.54]$ & $38.58[35.96-41.19]$ & $17.29[14.41-20.18]$ & $<0.001$ \\
DISH & $3.85[3.01-4.69]$ & $4.87[3.71-6.02]$ & $1.80[0.79-2.82]$ & 0.001 \\
\hline
\end{tabular}

[]: $95 \%$ confidence interval

C cervical, $T$ thoracic, $L$ lumbar, OPLL ossification of the posterior longitudinal ligament, OLF, ossification of the ligamentum flavum, $O A L L$ ossification of the anterior longitudinal ligament, ONL ossification of the nuchal ligament, DISH diffuse idiopathic skeletal hyperostosis

Of all cases of C-OALL, $13 \%$ had C-OPLL, $62 \%$ had ONL, 56\% had T-OLF, $69 \%$ had T-OALL, and 30\% had DISH. Of all cases of T-OALL, $7 \%$ had T-OPLL, $50 \%$ had T-OLF, $11 \%$ had C-OPLL, $24 \%$ had C-OALL, $51 \%$ had ONL, and $20 \%$ had DISH.

\section{Prevalence and concomitance of ONL and DISH}

A total of 630 subjects had ONL, including 515 men and 115 women. The prevalence of ONL was $31.5 \%$ (men, 38.6\%; women, 17.3\%). A total of 77 subjects had DISH, including 65 men and 12 women. The prevalence of DISH was $3.9 \%$ (men, $4.9 \%$; women, $1.8 \%$ ). The prevalence of ONL and DISH was significantly higher in males compared to females $(P<0.01)$ (Table 2, Fig. 2).
Of all cases of ONL, $6 \%$ had C-OPLL, 13\% had C-OALL, $43 \%$ had T-OLF, 31\% had T-OALL, and $8 \%$ had DISH. Of all cases of DISH, 18\% had C-OPLL, 10\% had T-OPLL, 57\% had T-OLF, and 65\% had ONL.

\section{Clinical factors correlated with spinal ligament ossification}

We compared the prevalence of OSL among each 10-year age group (Fig. 4). The prevalence revealed an increase trend in older age group. The average age of OSL-positive subjects was significantly higher than that of OSL-negative subjects (Tables 3 and 4).

C-OPLL-positive individuals had significantly higher weight and BMI than C-OPLL-negative $(P<0.001)$.

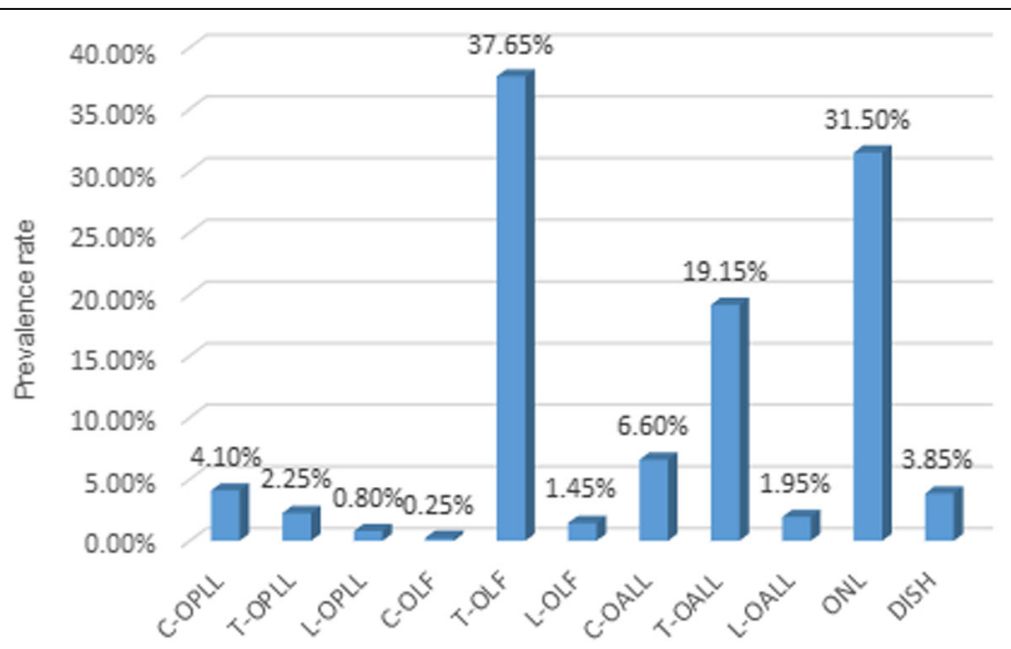

Fig. 2 Prevalence of each type of spinal ligament ossification. Abbreviations: C, cervical; T, thoracic; L, lumbar; OPLL, ossification of the posterior longitudinal ligament; OLF, ossification of the ligamentum flavum; OALL, ossification of the anterior longitudinal ligament; ONL, Ossification of the nuchal ligament; DISH, diffuse idiopathic skeletal hyperostosis 


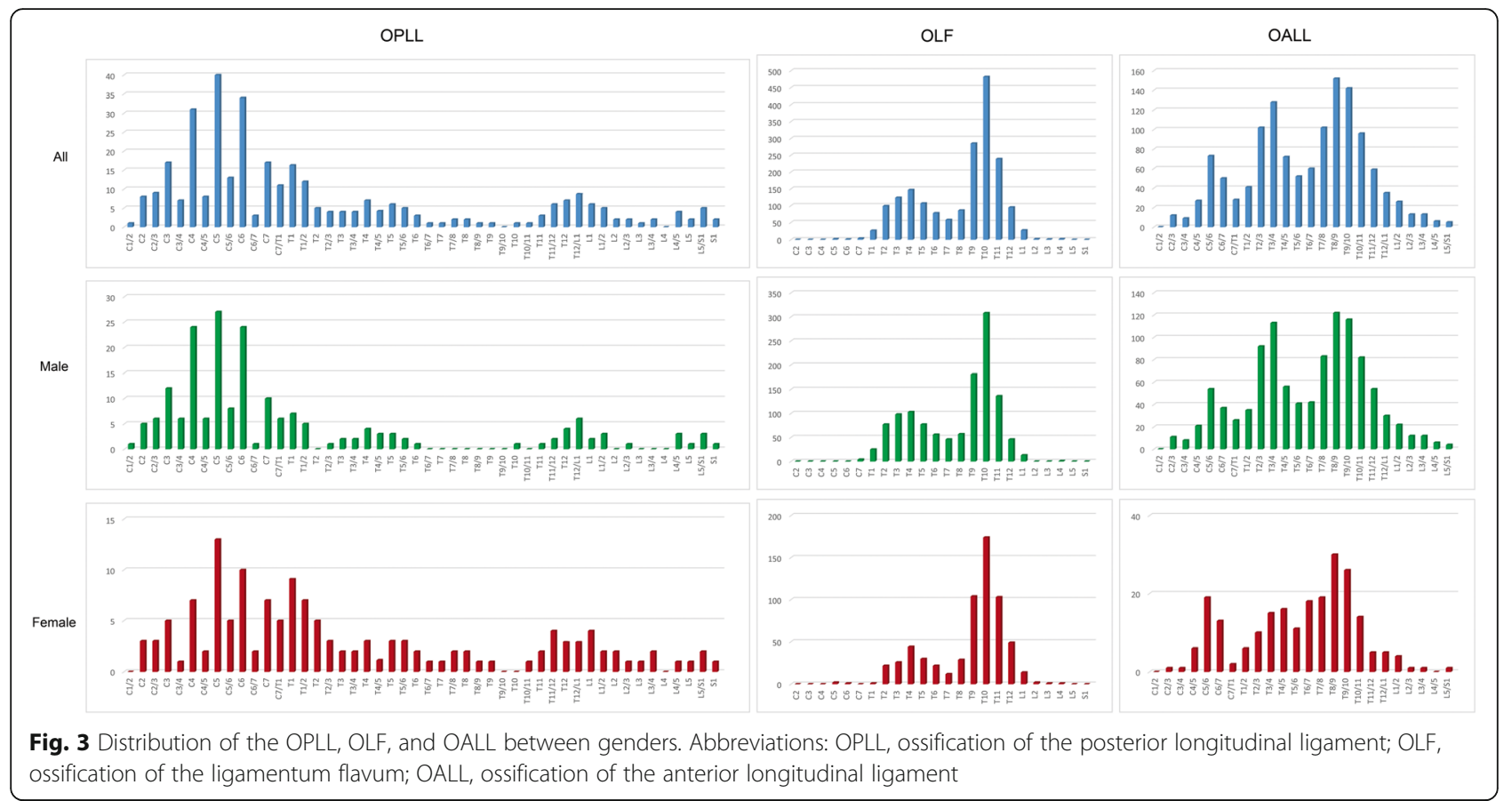

T-OLF-positive individuals had significantly higher TK, LL, and SS than T-OLF-negative $(P<0.01)$. ONL-positive individuals had significantly higher BMI and SVA than ONL-negative $(P<0.01)$. Individuals with T-OALL or DISH had significantly higher spinal sagittal parameters and BMI than those without. (Tables 3 and 4).

Figure 5 demonstrates the result of multivariate logistic regression analysis. Males showed a strong association with DISH (odds ratio, 3.15; 95\% confidence interval, $1.27-7.78 ; P=0.013)$. BMI was found to be significantly associated with the presence of C-OPLL and
DISH. In addition, increased age and TK were also found to be significant associated factors for the presence of T-OLF and DISH.

\section{Discussion}

The present study revealed the prevalence of OSL in the Chinese population. The prevalence rate of C-OPLL was 4.1\%, T-OPLL $2.25 \%$, L-OPLL $0.8 \%$; C-OLF $0.25 \%$, T-OLF 37.65\%, L-OLF 1.45\%; C-OALL 6.6\%, T-OALL 19.15\%, L-OALL 1.95\%; ONL 31.5\%; DISH 3.85\%. To the best of our knowledge, this study is the first to

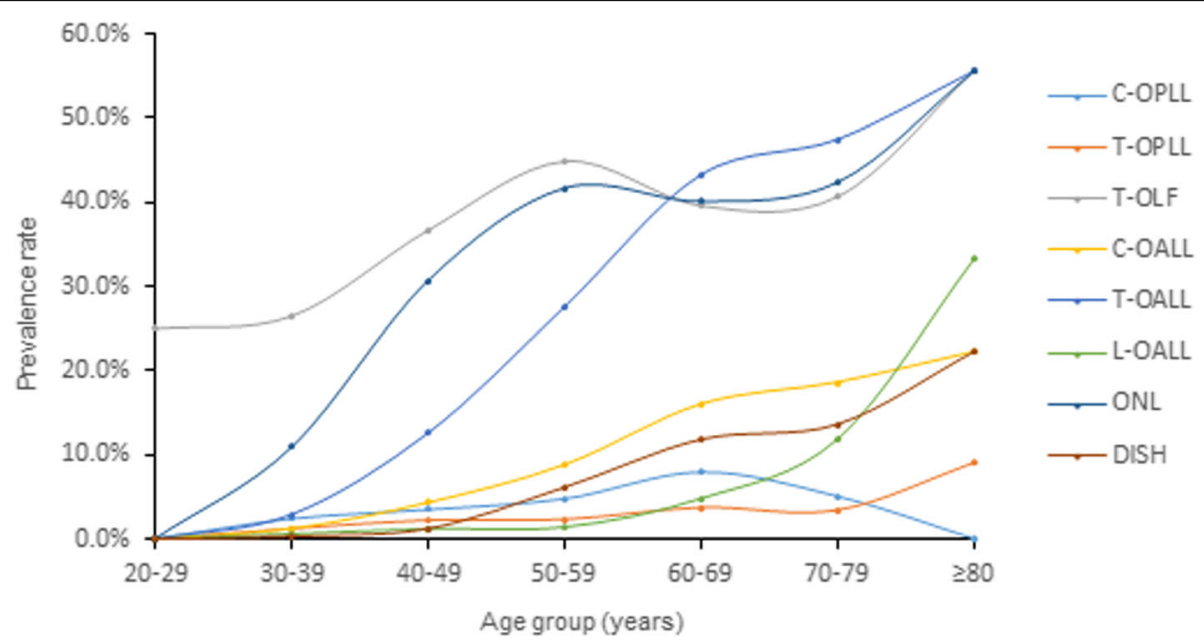

Fig. 4 The prevalence of spinal ligament ossification according to each decade of individuals' life. Abbreviations: C, cervical; T, thoracic; L, lumbar; OPLL, ossification of the posterior longitudinal ligament; OLF, ossification of the ligamentum flavum; OALL, ossification of the anterior longitudinal ligament; ONL, ossification of the nuchal ligament; DISH, diffuse idiopathic skeletal hyperostosis 
Table 3 Baseline characteristics of participants classified by the presence or absence of ossification

\begin{tabular}{|c|c|c|c|c|c|c|c|c|c|}
\hline \multirow[t]{2}{*}{ Number } & \multicolumn{3}{|l|}{ C-OPLL } & \multicolumn{3}{|l|}{ T-OPLL } & \multicolumn{3}{|l|}{ T-OLF } \\
\hline & $+(n=82)$ & $-(n=1918)$ & $p$ & $+(n=45)$ & $-(n=1955)$ & $p$ & $+(n=753)$ & $-(n=1247)$ & $p$ \\
\hline Age(y) & $51.7 \pm 9.1$ & $48.4 \pm 9.9$ & 0.003 & $51.8 \pm 11.2$ & $48.4 \pm 9.9$ & 0.026 & $49.7 \pm 9.7$ & $47.8 \pm 9.9$ & $<0.001$ \\
\hline Height(cm) & $167.3 \pm 7.6$ & $167.4 \pm 7.9$ & 0.941 & $166.1 \pm 7.9$ & $167.4 \pm 7.8$ & 0.259 & $167.1 \pm 7.7$ & $167.6 \pm 7.9$ & 0.257 \\
\hline Weight(kg) & $74.6 \pm 13.8$ & $68.5 \pm 12.5$ & $<0.001$ & $71.5 \pm 13.6$ & $68.7 \pm 12.6$ & 0.156 & $68.3 \pm 12.9$ & $69.1 \pm 12.4$ & 0.222 \\
\hline $\mathrm{BMI}\left(\mathrm{kg} / \mathrm{m}^{2}\right)$ & $26.5 \pm 3.8$ & $24.3 \pm 3.3$ & $<0.001$ & $25.8 \pm 3.3$ & $24.4 \pm 3.3$ & 0.008 & $24.3 \pm 3.4$ & $24.5 \pm 3.3$ & 0.364 \\
\hline $\mathrm{CL}\left({ }^{\circ}\right)$ & $8.2 \pm 7.1$ & $7.8 \pm 6.2$ & 0.648 & $8.5 \pm 8.2$ & $7.8 \pm 6.2$ & 0.479 & $8.0 \pm 6.3$ & $7.8 \pm 6.2$ & 0.380 \\
\hline $\mathrm{TK}\left(\left(^{\circ}\right)\right.$ & $16.8 \pm 7.0$ & $18.4 \pm 7.7$ & 0.073 & $19.1 \pm 8.8$ & $18.3 \pm 7.7$ & 0.505 & $19.2 \pm 8.1$ & $17.8 \pm 7.4$ & $<0.001$ \\
\hline $\operatorname{LL}\left({ }^{\circ}\right)$ & $38.9 \pm 9.1$ & $40.7 \pm 10.6$ & 0.128 & $41.2 \pm 11.1$ & $40.6 \pm 10.5$ & 0.708 & $41.8 \pm 10.7$ & $39.9 \pm 10.3$ & $<0.001$ \\
\hline $\mathrm{SS}\left({ }^{\circ}\right)$ & $35.9 \pm 6.6$ & $37.2 \pm 10.7$ & 0.293 & $37.4 \pm 7.6$ & $37.1 \pm 10.6$ & 0.853 & $37.5 \pm 7.7$ & $36.6 \pm 7.4$ & 0.008 \\
\hline $\mathrm{SVA}(\mathrm{cm})$ & $1.79 \pm 1.10$ & $1.88 \pm 2.00$ & 0.716 & $1.84 \pm 1.30$ & $1.87 \pm 1.99$ & 0.916 & $1.86 \pm 1.33$ & $1.88 \pm 2.28$ & 0.811 \\
\hline
\end{tabular}

$B M I$ body mass index, $C L$ cervical lordosis, $T K$ thoracic kyphosis, $L L$ lumbar lordosis, SS sacral slope, SVA sagittal vertical axis, $C$ cervical, $T$ thoracic, $L$ lumbar, OPLL ossification of the posterior longitudinal ligament, OLF ossification of the ligamentum flavum

comprehensively examine the prevalence of each type of OSL, using whole-body $\mathrm{CT}$, in the Chinese population and evaluate the factors that correlate with the presence of OSL.

OPLL and OLF could be a latent cause of neurologic symptoms induced by spinal cord compression. According to previous reports, the prevalence of C-OPLL was 1.9 to $6.3 \%$ in Japanese [16, 18, 22-24], 0.6 to $5.7 \%$ in Korean [25, 26], 4.8\% in Asian Americans [15], and 0.7 to $1.3 \%$ in Caucasian $[15,27]$. The prevalence of T-OLF was 3.6 to $36 \%$ in Japanese [16, 28-30], 3.8 to $63.9 \%$ in Chinese [9, 10], and 16.9 to $21.8 \%$ in Korean $[4,31]$. The prevalence of T-OPLL was 0.56 to $1.9 \%$ in Japanese [16, 30, 32]. Our CT-based study showed that the prevalence was $4.1 \%$ in C-OPLL, $37.65 \%$ in T-OLF, and $2.25 \%$ in T-OPLL. It was found that the prevalence results of this study in Chinese were roughly consistent with other eastern Asians. And the prevalence of C-OPLL in western Caucasians is relatively lower than in eastern Asians, suggesting that genetic or ethnic factor could be related with the onset of OPLL. High prevalence of T-OLF was found among eastern Asians. Few studies have assessed the prevalence of T-OLF among western Caucasians. Although T-OLF has been considered unusual among Caucasians [9, 29], Williams et al. [33] reported the prevalence of T-OLF was $26 \%$ in 100 western Caucasians using CT. However, due to the limitation in the number of studies and sample size, it is difficult to compare the prevalence of OLF between eastern Asians and western Caucasians. Future studies should address these limitations.

One must note that if we classified the above-mentioned prevalence by diagnostic modality, we could find the prevalence of OSL by CT scan was generally higher than that of previous reports using plain radiographs or MRI. These diverse results show that the diagnostic modality has a significant impact on the assessment of OSL. Plain radiograph is not sensitive enough to detect small ossifications. Because C-OPLL in the lower cervical spine is likely to be masked by shoulder girdle shadows $[14,26]$. T-OLF and T-OPLL are likely to be masked by superimposed bony structures such as ribs [29, 34]. MRI is also less sensitive for identifying small ossifications and thickened or folded ligamentum flavum $[4,10]$.

Table 4 Baseline characteristics of participants classified by the presence or absence of ossification

\begin{tabular}{|c|c|c|c|c|c|c|c|c|c|}
\hline \multirow[t]{2}{*}{ Number } & \multicolumn{3}{|l|}{ T-OALL } & \multicolumn{3}{|l|}{ ONL } & \multicolumn{3}{|l|}{$\mathrm{DISH}$} \\
\hline & $+(n=383)$ & $-(n=1617)$ & $p$ & $+(n=630)$ & $-(n=1370)$ & $p$ & $+(n=77)$ & $-(n=1923)$ & $p$ \\
\hline Age(y) & $55.2 \pm 9.6$ & $46.9 \pm 9.3$ & $<0.001$ & $51.7 \pm 9.2$ & $47.0 \pm 9.8$ & $<0.001$ & $58.7 \pm 9.4$ & $48.1 \pm 9.7$ & $<0.001$ \\
\hline Height(cm) & $167.7 \pm 7.6$ & $167.3 \pm 7.9$ & 0.356 & $169.2 \pm 7.0$ & $166.6 \pm 8.1$ & $<0.001$ & $167.7 \pm 7.5$ & $167.4 \pm 7.9$ & 0.753 \\
\hline Weight(kg) & $72.1 \pm 11.7$ & $68.0 \pm 12.7$ & $<0.001$ & $73.1 \pm 11.8$ & $66.7 \pm 12.5$ & $<0.001$ & $73.7 \pm 13.5$ & $68.6 \pm 12.5$ & 0.003 \\
\hline $\mathrm{BMI}\left(\mathrm{kg} / \mathrm{m}^{2}\right)$ & $25.5 \pm 3.1$ & $24.1 \pm 3.3$ & $<0.001$ & $25.4 \pm 3.2$ & $23.9 \pm 3.3$ & $<0.001$ & $26.1 \pm 3.7$ & $24.3 \pm 3.3$ & $<0.001$ \\
\hline $\mathrm{CL}\left({ }^{\circ}\right)$ & $8.9 \pm 7.4$ & $7.6 \pm 5.9$ & 0.002 & $7.8 \pm 6.2$ & $7.9 \pm 6.2$ & 0.879 & $10.9 \pm 8.4$ & $7.7 \pm 6.1$ & 0.001 \\
\hline $\mathrm{TK}\left({ }^{\circ}\right)$ & $22.2 \pm 9.6$ & $17.4 \pm 6.9$ & $<0.001$ & $19.2 \pm 8.0$ & $17.9 \pm 7.5$ & $<0.001$ & $24.4 \pm 9.6$ & $18.1 \pm 7.5$ & $<0.001$ \\
\hline $\mathrm{LL}\left({ }^{\circ}\right)$ & $43.4 \pm 10.4$ & $40.0 \pm 10.4$ & $<0.001$ & $40.3 \pm 10.6$ & $40.8 \pm 10.5$ & 0.399 & $43.5 \pm 9.9$ & $40.5 \pm 10.5$ & 0.013 \\
\hline $\mathrm{SS}\left({ }^{\circ}\right)$ & $38.2 \pm 7.4$ & $36.8 \pm 11.1$ & 0.027 & $36.6 \pm 7.3$ & $37.3 \pm 11.7$ & 0.148 & $37.9 \pm 7.1$ & $37.1 \pm 10.6$ & 0.511 \\
\hline SVA(cm) & $2.12 \pm 1.30$ & $1.81 \pm 2.10$ & 0.006 & $2.07 \pm 2.61$ & $1.78 \pm 1.59$ & 0.002 & $2.38 \pm 1.4$ & $1.85 \pm 1.99$ & 0.022 \\
\hline
\end{tabular}

$B M I$ body mass index, CL cervical lordosis, TK thoracic kyphosis, LL lumbar lordosis, SS sacral slope, SVA sagittal vertical axis, $T$ thoracic, OALL ossification of the anterior longitudinal ligament, ONL ossification of the nuchal ligament, DISH diffuse idiopathic skeletal hyperostosis 


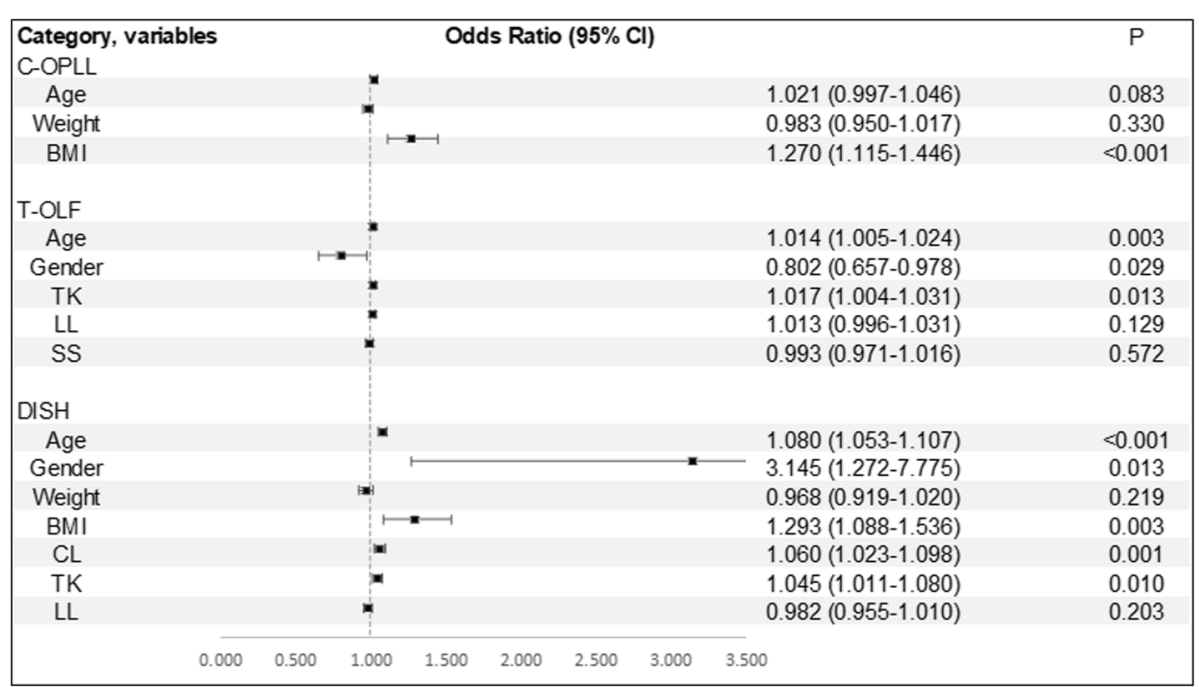

Fig. 5 Estimated associations (odds ratio [OR] and 95\% confidence interval) of selected demographic and clinical factors with spinal ligament ossification: results from multivariable logistic regression analyses. Abbreviations: BMl, body mass index; CL, cervical lordosis; TK, thoracic kyphosis; LL, lumbar lordosis; SS, sacral slope

CT has been shown to have higher sensitivity for identifying OSL and is more likely to discover the actual prevalence of OSL $[14,16,26,35]$.

Several reports have shown that tandem ossification is not uncommon in people with OSL [16, 36, 37]. Hirai et al. [36] and Kawaguchi et al. [37] revealed that more than half of the patients with neurological symptoms caused by C-OPLL had coexisting OPLL in the thoracolumbar spine. Fujimori et al. [16] reported that more than half of the individuals with T-OPLL also had C-OPLL and 46\% of T-OPLL also had T-OLF among general Japanese population. Similarly, in this study, we found that $21 \%$ of subjects with C-OPLL had T-OPLL, $44 \%$ of C-OPLL had T-OLF, $38 \%$ of T-OPLL had C-OPLL, 53\% of T-OPLL had T-OLF, 19\% of L-OPLL had C-OPLL, $44 \%$ of L-OPLL had T-OPLL, and $56 \%$ of L-OPLL had T-OLF among Chinese population. It can be found that subjects with OPLL generally have a predisposition to coexist with multiple-regional lesions. There is a high incidence of multiple-regional OPLL in the whole spine. In addition, it should be noted that approximately half of the subjects with OPLL coexist with T-OLF. Missed multiple-regional lesions can lead to serious consequences. Takeuchi et al. [38] reported case reports of thoracic paraplegia due to missed thoracic compressive lesion developing after a routine lumbar laminectomy. We suggest that it is not necessary to use whole spine $\mathrm{CT}$ as a routine screening. But, for patients with clinical symptoms induced by OPLL, we recommend thorough evaluation of whole spine using CT.

Tables 5 and 6 give a summary of studies performed by various authors on the prevalence of OSL by sex. Our data showed that T-OPLL is significantly more common in women, while DISH is significantly more common in men. The results of the multiple regression analysis revealed that males are three times more likely to suffer from DISH. Consistent with previous evidence $[6,16$, 32, 40, 41, 43-49], female preponderance of T-OPLL and male preponderance of DISH were confirmed. With regard to the gender difference in the prevalence of C-OPLL, our current study showed that the prevalence of C-OPLL in men is almost equal to that in women. (men $4.12 \%$, women $4.06 \%$ ). C-OPLL prevalence rate of men in our study is far lower than that of previous studies using CT scan $[16,26]$. In Japan and Korea, the prevalence has been considered to have a male predominance of roughly $2: 1$ to $3: 1$ [50]. Although eastern Asians are thought to be genetically similar, the discrepancy could be attributed to different reasons, such as age distribution, sex ratio, sample size, target population, or selection bias. In addition, lifestyle factors and dietary habits, including bad sleeping habits [51], high-salt and low-protein diet [52], were associated with an increased risk of OPLL. Some studies have shown that the coexistence of other disorders such as obesity [53], diabetes mellitus [54], hypoparathyroidism [5], and hormonal imbalance [55], are contributory factors in OPLL. Therefore, these multiple factors may lead to different results. For T-OLF, through a review of literature, we encountered 6 epidemiological studies reporting the prevalence of T-OLF. But the results regarding the gender difference in T-OLF prevalence are inconsistent. Four studies $[4,10,16,29]$ showed that T-OLF occurs predominantly in men, while two others $[9,31]$ showed the opposite result. In this study, T-OLF was significantly more common in women (men 36.10\%, women 40.75\%). 
Table 5 Previously reported prevalence of C-OPLL and T-OPLL

\begin{tabular}{|c|c|c|c|c|c|c|c|c|}
\hline \multirow[t]{2}{*}{ Type } & \multirow[t]{2}{*}{ Authors/reported year } & \multirow[t]{2}{*}{ Country } & \multirow[t]{2}{*}{ Race } & \multirow{2}{*}{$\begin{array}{l}\text { Sample } \\
\text { Size }\end{array}$} & \multirow[t]{2}{*}{ Modality } & \multicolumn{3}{|c|}{ Prevalence rate } \\
\hline & & & & & & M (\%) & $F(\%)$ & $\mathrm{T}(\%)$ \\
\hline \multirow[t]{12}{*}{ C-OPLL } & Firooznia et al. [39]/1984 & USA & White & 1000 & Cervical x-ray & NA & NA & 0.7 \\
\hline & Ohtsuka et al. [23]/1987 & Japan & Asian & 1058 & $x$-ray & 4.3 & 2.4 & 3.2 \\
\hline & Shingyouchi et a [18]/1996 & Japan & Asian & 4802 & Cervical x-ray & NA & NA & 4.1 \\
\hline & Kim et al. [25]/2008 & Korea & Asian & 11,774 & Cervical x-ray & 0.79 & 0.45 & 0.6 \\
\hline & Yoshimura et al. [24]/2014 & Japan & Asian & 1562 & Cervical x-ray & 3.2 & 1.3 & 1.9 \\
\hline & Sohn et al. [26]/2014 & Korea & Asian & 3240 & Thyroid CT & 8.8 & 4.2 & 5.7 \\
\hline & Fujimori et al. [15]/2015 & USA & White & 1593 & Cervical CT & 1.6 & 0.8 & 1.3 \\
\hline & & & Asian & 624 & Cervical CT & 5.8 & 3.6 & 4.8 \\
\hline & & & Hispanic & 472 & Cervical CT & 1.5 & 3.1 & 1.9 \\
\hline & & & Aframerican & 326 & Cervical CT & 2.2 & 2.0 & 2.1 \\
\hline & Fujimori et al. [16]/2016 & Japan & Asian & 1500 & PETCT & 8.3 & 3.4 & 6.3 \\
\hline & Present study & China & Asian & 2000 & PETCT & 4.12 & 4.06 & 4.10 \\
\hline \multirow[t]{5}{*}{ T-OPLL } & Ono et al. [32]/1982 & Japan & Asian & 8610 & Chest x-ray & 0.25 & 0.74 & 0.56 \\
\hline & Ohtsuka et al. [30]/1986 & Japan & Asian & 1058 & x-ray & 0.9 & 0.6 & 0.8 \\
\hline & Mori et al. [40]/2014 & Japan & Asian & 3013 & Chest CT & 1.0 & 3.0 & 1.9 \\
\hline & Fujimori et al. [16]/2016 & Japan & Asian & 1500 & PETCT & 1.4 & 2.0 & 1.6 \\
\hline & Present study & China & Asian & 2000 & PETCT & 1.57 & 3.61 & 2.25 \\
\hline
\end{tabular}

$T$ total, $M$ male, $F$ female, C-OPLL ossification of the posterior longitudinal ligament of the cervical spine, $T$-OPLL ossification of the posterior longitudinal ligament of the thoracic spine, CT computed tomography, NA not available, PETCT positron emission tomography and computed tomography

Table 6 Previously reported prevalence of T-OLF and DISH

\begin{tabular}{|c|c|c|c|c|c|c|c|c|}
\hline \multirow[t]{2}{*}{ Type } & \multirow[t]{2}{*}{ Authors/reported year } & \multirow[t]{2}{*}{ Country } & \multirow[t]{2}{*}{ Race } & \multirow{2}{*}{$\begin{array}{l}\text { Sample } \\
\text { Size }\end{array}$} & \multirow[t]{2}{*}{ Modality } & \multicolumn{3}{|c|}{ Prevalence rate } \\
\hline & & & & & & M (\%) & $F(\%)$ & $\mathrm{T}(\%)$ \\
\hline \multirow[t]{7}{*}{ T-OLF } & Guo et al. [9]/2010 & China & Asian & 1736 & $\mathrm{MRI}, \mathrm{CT}$ & 2.1 & 4.87 & 3.8 \\
\hline & Mori et al. [29]/2013 & Japan & Asian & 3013 & Chest CT & 38 & 33.9 & 36 \\
\hline & Lang et al. [10]/2013 & China & Asian & 993 & Chest CT & 68.5 & 59 & 63.9 \\
\hline & Moon et al. [31]/2015 & Korea & Asian & 2134 & MRI & 13.7 & 19 & 16.9 \\
\hline & Fujimori et al. [16]/2016 & Japan & Asian & 1500 & PETCT & 15 & 7.7 & 12 \\
\hline & Kim et al. [4]/2018 & Korea & Asian & 4999 & Chest CT & 23 & 20.1 & 21.8 \\
\hline & Present study & China & Asian & 2000 & PETCT & 36.10 & 40.75 & 37.65 \\
\hline \multirow[t]{12}{*}{ DISH } & Julkunen et al. [41]/1975 & Finland & White & 8993 & Chest x-ray & 3.8 & 2.6 & 2.6 \\
\hline & Cassim et al. [42]/1990 & South Africa & African & 1500 & Chest x-ray & 3.8 & 4.2 & 3.9 \\
\hline & Weinfeld et al. [43]/1997 & USA & Mixed race & 2364 & Chest x-ray & 25 & 15 & NA \\
\hline & Kiss et al. [44]/2002 & Hungary & White & 635 & x-ray & 27.3 & 12.8 & 19.8 \\
\hline & Kim et al. [45]/2004 & Korea & Asian & 3595 & Chest x-ray & 5.4 & 0.8 & 2.9 \\
\hline & Westerveld et al. [46]/2008 & Netherlands & White & 501 & Chest x-ray & 22.7 & 12.1 & 17 \\
\hline & Kagotani et al. [6]/2015 & Japan & Asian & 1647 & Whole spine $x$-ray & 22 & 4.8 & 11 \\
\hline & Hirasawa et al. [47]/2016 & Japan & Asian & 558 & Chest-pelvis CT & 38.7 & 13.9 & 27.2 \\
\hline & Fujimori et al. [16]/2016 & Japan & Asian & 1500 & PETCT & 16 & 6.2 & 12 \\
\hline & Mori et al. [48]/2017 & Japan & Asian & 3013 & Chest CT & 13 & 2.5 & 8.7 \\
\hline & Hiyama et al. [49]/2018 & Japan & Asian & 1479 & Whole spine $C T$ & 21.1 & 16 & 19.5 \\
\hline & Present study & China & Asian & 2000 & PETCT & 4.87 & 1.80 & 3.85 \\
\hline
\end{tabular}

$T$ total, $M$ male, $F$ female, $T$-OLF ossification of the ligamentum flavum of the thoracic spine, DISH diffuse idiopathic skeletal hyperostosis, $C T$ computed tomography, NA not available, PETCT, positron emission tomography and computed tomography, MRI magnetic resonance imaging 
Additional large-scale, multi-center studies is therefore necessary to confirm the cause for these differences.

Our study showed the mean age of people with ossifications was significantly higher than those without. OSL is more prevalent in the older age group. We found that increasing age was significantly associated with the presence of T-OLF or DISH. This finding suggests that degeneration factor might affect the development of OSL. By multiple logistic regression analysis, we found that TK was significantly related to the presence of T-OLF and DISH. Similarly, Kim et al. [4] reported that people with T-OLF had significantly higher TK than others and believed that this suggested T-OLF was associated with mechanical stress. Because thoracic spine with greater TK often accompanied by higher tensile force. In the present study, T-OLF most frequently located in lower thoracic segments (T9-T12) and the second most frequent location was the upper thoracic segments (T2T5). T-OPLL most frequently located in cervicothoracic junction region (T1-T2). Several studies considered that these locations are transitional areas in terms of spinal curvature, where is the area of high stress concentration $[2,4,9,10]$. Therefore, it is possibly more prone to degeneration because of the high tensile forces.

The present study has several limitations. First, the study population was not randomly selected and not purely based on the general population. All individuals were collected in a tertiary, multi-specialty referral hospital, which inevitably creates a sample selection bias. However, it is considered unethical to perform whole body $\mathrm{CT}$ for normal volunteers due to the radiation exposure. Second, there are 59 subjects (3.0\%) might suffer from cancer in the study sample. Incidence of cancer in our study was higher than the real cancer morbidity [56]. But through statistical analysis, we found that there is no significant difference in the prevalence of spinal ligament ossification between cancer-positive subjects and cancer-negative subjects (data not shown). Third, there is no information regarding the clinical presentation of OSL in this screening population. We could not evaluate the association between OSL and related clinical manifestations. Fourth, spinal sagittal parameters measured from supine position may be underestimated compared with standing position. In addition, OSL can have an influence on the flexibility of the spinal column, so there may be a limitation for measuring spinal sagittal parameters in the supine position. Nevertheless, considering the difficulty in obtaining whole body CT data in a large general population, we think that our data, to some extent, reflects the prevalence of OSL in the general population of China.

\section{Conclusions}

The prevalence of spinal ligament ossifications in Chinese was revealed and roughly consistent with other eastern Asians. Tandem ossification is not uncommon in people with spinal ligament ossifications. There is a high incidence of multiple-regional OPLL in the whole spine. Approximately half of the subjects with OPLL coexist with T-OLF. For patients with clinical symptoms induced by OPLL, thorough evaluation of whole spine using $\mathrm{CT}$ is recommended.

\section{Abbreviations \\ BMI: Body mass index; C: Cervical; CL: Cervical lordosis; CT: Computed tomography; DISH: Diffuse idiopathic skeletal hyperostosis; L: Lumbar; LL: Lumbar lordosis; MRI: Magnetic resonance imaging; OALL: Ossification of the anterior longitudinal ligament; OLF: Ossification of the ligamentum flavum; ONL: Ossification of the nuchal ligament; OPLL: Ossification of the posterior longitudinal ligament; OSL: Ossification of the spinal ligaments; SS: Sacral slope; SVA: Sagittal vertical axis; T: Thoracic; TK: Thoracic kyphosis}

\section{Acknowledgements}

Not applicable

\section{Funding}

No funds were received in support of this work.

\section{Availability of data and materials}

The datasets used and analysed during the current study available from the corresponding author on reasonable request.

\section{Authors' contributions}

QMF, HFL, GBL, and HCS were involved in all the work of the article. SYL and DJJ were involved in the data collection and analysis. SGC was involved in data collection. All authors read and approved the final manuscript.

\section{Ethics approval and consent to participate}

This study was approved by the Ethics Committee of the Zhongshan Hospital, Fudan University.

The participant consent was written, and was performed in accordance with the ethical standards of the Declaration of Helsinki of 1964.

\section{Consent for publication}

Not applicable

\section{Competing interests}

The authors declare that they have no competing interests.

\section{Publisher's Note}

Springer Nature remains neutral with regard to jurisdictional claims in published maps and institutional affiliations.

Received: 21 September 2018 Accepted: 12 April 2019

Published online: 25 May 2019

\section{References}

1. Li H, Jiang L-S, Dai L-Y. Hormones and growth factors in the pathogenesis of spinal ligament ossification. Eur Spine J. 2007;16:1075-84.

2. Tsukamoto N, Maeda T, Miura H, Jingushi S, Hosokawa A, Harimaya K, et al. Repetitive tensile stress to rat caudal vertebrae inducing cartilage formation in the spinal ligaments: a possible role of mechanical stress in the development of ossification of the spinal ligaments. J Neurosurg Spine. 2006:5:234-42.

3. Hirai T, Yoshii T, Nagoshi N, Takeuchi K, Mori K, Ushio S, et al. Distribution of ossified spinal lesions in patients with severe ossification of the posterior longitudinal ligament and prediction of ossification at each segment based on the cervical OP index classification: a multicenter study (JOSL CT study). BMC Musculoskelet Disord. 2018;19:107. 
4. Kim S-I, Ha K-Y, Lee J-W, Kim Y-H. Prevalence and related clinical factors of thoracic ossification of the ligamentum flavum - a computed tomographybased cross-sectional study. Spine J. 2018;18:551-7.

5. Inamasu J, Guiot BH, Sachs DC. Ossification of the posterior longitudinal ligament: an update on its biology, epidemiology, and natural history. Neurosurgery. 2006;58:1027-39.

6. Kagotani R, Yoshida M, Muraki S, Oka H, Hashizume H, Yamada $H$, et al. Prevalence of diffuse idiopathic skeletal hyperostosis (DISH) of the whole spine and its association with lumbar spondylosis and knee osteoarthritis: the ROAD study. J Bone Miner Metab. 2015;33:221-9.

7. Mader R. Clinical manifestations of diffuse idiopathic skeletal hyperostosis of the cervical spine. Semin Arthritis Rheum. 2002;32:130-5.

8. Mader R, Verlaan JJ, Buskila D. Diffuse idiopathic skeletal hyperostosis: clinical features and pathogenic mechanisms. Nat Rev Rheumatol. 2013;9:741-50.

9. Guo JJ, Luk KD, Karppinen J, Yang H, Cheung K. Prevalence, distribution, and morphology of ossification of the ligamentum flavum: a population study of one thousand seven hundred thirty-six magnetic resonance imaging scans. Spine (Phila Pa 1976). 2010;35:51-6.

10. Lang N, Yuan HS, Wang HL, Liao J, Li M, Guo FX, et al. Epidemiological survey of ossification of the ligamentum flavum in thoracic spine: $C T$ imaging observation of 993 cases. Eur Spine J. 2013;22:857-62.

11. Wang H, Zou F, Jiang J, Lu F, Chen W, Ma X, et al. Analysis of radiography findings of ossification of nuchal ligament of cervical spine in patients with cervical spondylosis. Spine (Phila Pa 1976). 2014;39:E7-11.

12. Xiong $L$, Zeng $Q$, Jinkins J. CT and MRI characteristics of ossification of the ligamenta flava in the thoracic spine. Eur Radiol. 2001;11:1798-802.

13. Chiba K, Kato Y, Tsuzuki N, Nagata K, Toyama Y, Iwasaki M, et al. Computerassisted measurement of the size of ossification in patients with ossification of the posterior longitudinal ligament in the cervical spine. J Orthop Sci. 2005;10:451-6.

14. Fujimori T, Iwasaki M, Nagamoto $Y$, Ishii T, Sakaura H, Kashii M, et al. Threedimensional measurement of growth of ossification of the posterior longitudinal ligament. J Neurosurg Spine. 2012;16:289-95

15. Fujimori T, Le H, Hu SS, Chin C, Pekmezci M, Schairer W, et al. Ossification of the posterior longitudinal ligament of the cervical spine in 3161 patients: a CT-based study. Spine (Phila Pa 1976). 2015;40:E394-403.

16. Fujimori T, Watabe T, Iwamoto Y, Hamada S, Iwasaki M, Oda T. Prevalence, concomitance, and distribution of ossification of the spinal ligaments: results of whole spine CT scans in 1500 Japanese patients. Spine (Phila Pa 1976). 2016:41:1668-76.

17. Tsuyama N. Ossification of the posterior longitudinal ligament of the spine. Clin Orthop Relat Res. 1984;184:71-84.

18. Shingyouchi $Y$, Nagahama A, Niida M. Ligamentous Ossification of the Cervical Spine in the Late Middle-Aged Japanese Men: Its Relation to Body Mass Index and Glucose Metabolism. Spine (Phila Pa 1976). 1996;21:2474-8.

19. Resnick D, Niwayama G. Radiographic and pathologic features of spinal involvement in diffuse idiopathic skeletal hyperostosis (DISH). Radiology. 1976;119:559-68.

20. Adam CJ, Izatt MT, Harvey JR, Askin GN. Variability in Cobb angle measurements using reformatted computerized tomography scans. Spine (Phila Pa 1976). 2005;30:1664-9.

21. Landis JR, Koch GG. The measurement of observer agreement for categorical data. Biometrics. 1977;33:159-74.

22. Matsunaga S, Sakou T. Ossification of the posterior longitudinal ligament of the cervical spine: etiology and natural history. Spine (Phila Pa 1976). 2012; 37:E309-14

23. Ohtsuka K, Terayama K, Yanagihara M, Wadal K, Kasuga K, Machida T, et al. A radiological population study on the ossification of the posterior longitudinal ligament in the spine. Arch Orthop Trauma Surg. 1987;106: 89-93.

24. Yoshimura N, Nagata K, Muraki S, Oka H, Yoshida M, Enyo Y, et al. Prevalence and progression of radiographic ossification of the posterior longitudinal ligament and associated factors in the Japanese population: a 3-year follow-up of the ROAD study. Osteoporos Int. 2014;25:1089-98.

25. Kim T-J, Bae K-W, Uhm W-S, Kim T-H, Joo K-B, Jun J-B. Prevalence of ossification of the posterior longitudinal ligament of the cervical spine. Joint Bone Spine. 2008;75:471-4

26. Sohn S, Chung CK, Yun TJ, Sohn CH. Epidemiological survey of ossification of the posterior longitudinal ligament in an adult Korean population: threedimensional computed tomographic observation of 3,240 cases. Calcif Tissue Int. 2014;94:613-20.
27. Firooznia H, Benjamin V, Pinto R, Golimbu C, Rafii M, Leitman B, et al. Calcification and ossification of posterior longitudinal ligament of spine: its role in secondary narrowing of spinal canal and cord compression. N Y State J Med. 1982:82:1193-8.

28. Kudo S, Ono M, Russell W. Ossification of thoracic ligamenta flava. AJR Am J Roentgenol. 1983;141:117-21.

29. Mori K, Kasahara T, Mimura T, Nishizawa K, Murakami Y, Matsusue Y, et al. Prevalence, distribution, and morphology of thoracic ossification of the yellow ligament in Japanese: results of CT-based cross-sectional study. Spine (Phila Pa 1976). 2013;38:E1216-22.

30. Ohtsuka K, Terayama K, Yanagihara M, Wada K, Kasuga K, Machida T, et al. An epidemiological survey on ossification of ligaments in the cervical and thoracic spine in individuals over 50 years of age. Nihon Seikeigeka Gakkai Zasshi. 1986;60:1087-98.

31. Moon BJ, Kuh SU, Kim S, Kim KS, Cho YE, Chin DK. Prevalence, distribution, and significance of incidental thoracic ossification of the ligamentum flavum in Korean patients with back or leg pain: MR-based cross sectional study. J Korean Neurosurg Soc. 2015;58:112-8.

32. Ono M, Russell W, Kudo S, Kuroiwa Y, Takamori M, Motomura S, et al. Ossification of the thoracic posterior longitudinal ligament in a fixed population. Radiological and neurological manifestations. Radiology. 1982; 143:469-74.

33. Williams D, Gabrielsen T, Latack J, Martel W, Knake J. Ossification in the cephalic attachment of the ligamentum flavum. An anatomical and CT study. Radiology. 1984;150:423-6.

34. Okada G, Hosoi S, Kato K, Ohta K, Tachi Y, Sonoda J, et al. Case report 779 Carbonate apatite calcification of ligamentum flavum. Skelet Radiol. 1993;22: 211-3.

35. Chang $\mathrm{H}$, Kong $\mathrm{C}-\mathrm{G}$, Won $\mathrm{H}-\mathrm{Y}$, Kim J-H, Park J-B. Inter-and intra-observer variability of a cervical OPLL classification using reconstructed $C T$ images. Clin Orthop Surg. 2010;2:8-12.

36. Hirai T, Yoshii T, Iwanami A, Takeuchi K, Mori K, Yamada T, et al. Prevalence and distribution of ossified lesions in the whole spine of patients with cervical ossification of the posterior longitudinal ligament a multicenter study (JOSL CT study). PLoS One. 2016;11:e0160117.

37. Kawaguchi Y, Nakano M, Yasuda T, Seki S, Hori T, Kimura T. Ossification of the posterior longitudinal ligament in not only the cervical spine, but also other spinal regions: analysis using multidetector computed tomography of the whole spine. Spine (Phila Pa 1976). 2013;38:E1477-82.

38. Takeuchi A, Miyamoto K, Hosoe H, Shimizu K. Thoracic paraplegia due to missed thoracic compressive lesions after lumbar spinal decompression surgery: report of three cases. J Neurosurg Spine. 2004;100:71-4.

39. Firooznia H, Rafii M, Golimbu C, Tyler I, Benjamin V, Pinto R. Computed tomography of calcification and ossification of posterior longitudinal ligament of the spine. J Comput Tomogr. 1984;8:317-24.

40. Mori K, Imai S, Kasahara T, Nishizawa K, Mimura T, Matsusue Y. Prevalence, distribution, and morphology of thoracic ossification of the posterior longitudinal ligament in Japanese: results of CT-based cross-sectional study. Spine (Phila Pa 1976). 2014;39:394-9.

41. Julkunen $\mathrm{H}$, Heinonen OP, Knekt P, Maatela J. The epidemiology of hyperostosis of the spine together with its symptoms and related mortality in a general population. Scand J Rheumatol. 1975;4:23-7.

42. Cassim B, Mody GM, Rubin DL. The prevalence of diffuse idiopathic skeletal hyperostosis in African blacks. Br J Rheumatol. 1990;29:131-2.

43. Weinfeld RM, Olson PN, Maki DD, Griffiths HJ. The prevalence of diffuse idiopathic skeletal hyperostosis (DISH) in two large American Midwest metropolitan hospital populations. Skelet Radiol. 1997;26: 222-5.

44. Kiss C, O'Neill TW, Mituszova M, Szilagyi M, Poor G. The prevalence of diffuse idiopathic skeletal hyperostosis in a population-based study in Hungary. Scand J Rheumatol. 2002;31:226-9.

45. Kim SK, Choi BR, Kim CG, Chung SH, Choe JY, Joo KB, et al. The prevalence of diffuse idiopathic skeletal hyperostosis in Korea. J Rheumatol. 2004;31: 2032-5.

46. Westerveld LA, van Ufford HM, Verlaan JJ, Oner FC. The prevalence of diffuse idiopathic skeletal hyperostosis in an outpatient population in the Netherlands. J Rheumatol. 2008;35:1635-8.

47. Hirasawa A, Wakao N, Kamiya M, Takeuchi M, Kawanami K, Murotani K, et al. The prevalence of diffuse idiopathic skeletal hyperostosis in Japan-the first report of measurement by $\mathrm{CT}$ and review of the literature. J Orthop Sci. 2016;21:287-90 
48. Mori K, Kasahara T, Mimura T, Nishizawa K, Nakamura A, Imai S. Prevalence of thoracic diffuse idiopathic skeletal hyperostosis (DISH) in Japanese: results of chest CT-based cross-sectional study. J Orthop Sci. 2017;22:38-42.

49. Hiyama A, Katoh H, Sakai D, Sato M, Tanaka M, Watanabe M. Prevalence of diffuse idiopathic skeletal hyperostosis (DISH) assessed with whole-spine computed tomography in 1479 subjects. BMC Musculoskelet Disord. 2018; 19:178.

50. Matsunaga S, Nakamura K, Seichi A, Yokoyam T, Toh S, Ichimura S, et al. Radiographic predictors for the development of myelopathy in patients with ossification of the posterior longitudinal ligament: a multicenter cohort study. Spine (Phila Pa 1976). 2008:33:2648-50.

51. Washio M, Kobashi G, Okamoto K, Sasaki S, Yokoyama T, Miyake Y, et al. Sleeping habit and other life styles in the prime of life and risk for ossification of the posterior longitudinal ligament of the spine (OPLL): a case-control study in Japan. J Epidemiol. 2004:14:168-73.

52. Okamoto K, Kobashi G, Washio M, Sasaki S, Yokoyama T, Miyake Y, et al. Dietary habits and risk of ossification of the posterior longitudinal ligaments of the spine (OPLL); findings from a case-control study in Japan. J Bone Miner Metab. 2004;22:612-7.

53. Kobashi G, Washio M, Okamoto K, Sasaki S, Yokoyama T, Miyake Y, et al. High body mass index after age 20 and diabetes mellitus are independent risk factors for ossification of the posterior longitudinal ligament of the spine in Japanese subjects: a case-control study in multiple hospitals. Spine (Phila Pa 1976). 2004:29:1006-10.

54. Akune T, Ogata N, Seichi A, Ohnishi I, Nakamura K, Kawaguchi H. Insulin secretory response is positively associated with the extent of ossification of the posterior longitudinal ligament of the spine. J Bone Joint Surg Am. 2001;83:1537-44.

55. Musha Y. Etiological study of spinal ligament ossification with special reference to dietary habits and serum sex hormones. Nihon Seikeigeka Gakkai zasshi. 1990;64:1059-71.

56. Chen W, Zheng R, Zhang S, Zeng H, Zuo T, Xia C, et al. Cancer incidence and mortality in China in 2013: an analysis based on urbanization level. Chin J Cancer Res. 2017;29:1-10.

Ready to submit your research? Choose BMC and benefit from:

- fast, convenient online submission

- thorough peer review by experienced researchers in your field

- rapid publication on acceptance

- support for research data, including large and complex data types

- gold Open Access which fosters wider collaboration and increased citations

- maximum visibility for your research: over $100 \mathrm{M}$ website views per year

At $\mathrm{BMC}$, research is always in progress.

Learn more biomedcentral.com/submissions 